\title{
A new approach to evaluate railways efficiency considering safety measures
}

\author{
Ali Noroozzadeh ${ }^{\mathbf{a}^{*}}$ and Seyed Jafar Sadjadi ${ }^{\mathrm{b}}$
}

${ }^{a}$ Department of Rail Road Engineering, Iran University of Science \& Technology, Tehran, Iran

${ }^{b}$ Department of Industrial Engineering, Iran University of Science \& Technology, Tehran, Iran, Member of Center of Excellent of Industrial Engineering

\section{H R O N I C L E}

Article history:

Received October 2, 2012

Received in Revised Format

January 23, 2013

Accepted February 15, 2013

Available online

February 232013

Keywords:

Data envelopment analysis

Railroad industry

Efficiency

\section{A B S T R A C T}

\begin{abstract}
Safety is one of the main reasons for choosing railway to other transportation modes and improvement of transportation safety has attracted many researchers in recent years. In this paper, we aim to investigate the influence of safety measures on railways performance evaluation, empirically. The proposed model of this paper uses data envelopment analysis (DEA) to estimate the railways efficiency scores in the presence of safety measure. According to three proposed factors, the most appropriate model is selected to compare its result with output-oriented DEA model. The results of the survey are surprising since inefficient railroads become efficient through adding undesirable outputs in evaluation model.
\end{abstract}

\section{Introduction}

Railway transportation is one of the basic infrastructures of economic development. There are a number of factors, which turn people on to use railway transportation instead of other facilities, such as safety and inexpensive traveling expenditures. Over the past several decades, many researchers have struggled to assess the performance of railway transportation. Fielding et al. (1985) introduced three indicators for transportation system including cost efficiency, service effectiveness and cost effectiveness. Karlaftis (2004) used data envelopment analysis (DEA) to examine two significant topics in transportation: first, the relationship between efficiency and effectiveness as two indicators of performance evaluation; second, the relationship between performance and scale economies. Yu and Lin (2008) presented a multi-activity network DEA model to evaluate passenger and freight technical efficiency, service effectiveness and technical effectiveness for 20 selected railways in 2002. Jain et al. (2008) applied DEA to analyze the relationship between ownership structure and technical efficiency. They considered the impact of globalization and urbanization on several urban

* Corresponding author. Tel: +9877240129

E-mail addresses: ali_noroozzadeh@rail.iust.ac.ir (A. Noroozzadeh)

C 2013 Growing Science Ltd. All rights reserved.

doi: $10.5267 /$ j.ds1.2013.02.003 
railway transportation systems (URTS) of many cities in different countries. Chiu et al. (2011) proposed a value-chain model, which integrates the concept of undesirable intermediate, intermediate input, uncontrollable input and undesirable output. They used the model to evaluate the efficiency of 30 regions of China. Oum and Yu (1994) determined the impact of government policy and subsidization on the railways efficiency where passenger services play an important role in their economies. They measured the productive efficiency of the railway systems in 19 OECD countries and set the influence of both public subsidies and the degree of managerial autonomy on efficiency. Cowie (1999) studied Swiss rail industry and considered the effect of public and private ownership on technical efficiency.

In this paper, we propose a DEA approach for railway performance evaluation, by considering safety measures. The remainder of this paper is organized as follows. Section 2 reviews inputs and outputs, which are applied by other researchers in railway performance evaluation and the effects of safety measures on evaluation. Section 3, includes a brief description of DEA models applied in this paper. In section 4, the sample data are described, the proposed approach is explained and empirical results are presented. Eventually section 5 concludes the paper.

\section{Assessing railway performance}

\subsection{Input and output definition}

In Pervious researches, the role of safety measures has been ignored in evaluating railway efficiency. Those researches used several inputs and one or more desirable outputs to assess railways efficiency. Oum and Yu (1994) used labor, energy consumption, ways and structure, materials, the number of passenger cars, freight cars and, locomotives as inputs while passenger-train-kilometer and freighttrain-kilometer are considered as outputs. Jain et al. (2008) used the number of employees, the number of train cars and electric multiple units as well as the total network length of lines as inputs and train-car-kilometers as output for urban railway performance evaluation. Lawrence and Erwin (2003) pointed out that management did not control some factors such as population density, per capita gross national income and density of line, which influence on railway performance evaluation.

\subsection{Impact of safety on railway performance evaluation}

Due to the important role of safety in railway transportation, many people prefer to use such railbased services as their first choice. Since there is no significant effort to investigate the impact of the safety on the railway performance, we propose to use some safety measures to evaluate the railway performance comprehensively. These measures should be chosen in such an effective way that reflects safety characteristics of railways .

Facing railway casualty is inevitable. However, railway industry is the safest way of transporting people and goods; it does not mean that we should ignore safety in railroad efficiency evaluation. The main category associated with railroad safety is losses of accidents .

Losses of accidents are classified into the total number of accidents and the total number of victims in railroad accidents, annually. The total number of accidents covers minimum level of safety. Any accident, even with no major damage lied in this category. Whereas the total number of victims point to maximum level of safety needed to avoid these accidents. The concept of accident in this paper consists of collision of trains, derailments of train, level crossing accident, accidents to person caused by rolling stock in motion and fires in rolling stock.

The two above mentioned safety indicators in railway performance evaluation, should be used as outputs. Conventional outputs obtained directly from consuming inputs, are desirable, but safety measures proposed here are undesirable, so they should be decreased. Using the traditional DEA 
approaches misleads us, then we should use an approach that discriminate different outputs. Section 3 presents some DEA approaches that apply undesirable outputs in performance evaluation.

\section{Methodology}

Measuring comparative efficiency of decision-making units (DMU) has attracted many researchers. Performance evaluation methods could be classified into parametric and non-parametric methods based on the status of production function. Parametric methods such as stochastic frontier analysis (SFA) require production function to estimate the efficiency of under evaluation units. On the other hand, non-parametric methods do not require any specification about production function.

\subsection{Traditional DEA approaches}

DEA utilizes linear programming to evaluate performance of those DMUs, which uses the same inputs to produce the same outputs. Generally, DEA models are divided into two basic groups: input-oriented and output-oriented models. The purpose of input-oriented models is to decrease inputs with fixing outputs, while output-oriented models focus on increasing outputs with fixing inputs. According to Banker et al. (1984), output-oriented DEA model under the assumption of variable return to scale is described as follow:

$\max \varphi$

subject to

$$
\begin{array}{ll}
\sum_{j=1}^{n} x_{i j} \lambda_{j} \leq x_{i o} & i=1,2, \ldots, m \\
\sum_{j=1}^{n} y_{r j} \lambda_{j} \geq \varphi y_{r o} & r=1,2, . ., S \\
\sum_{j=1}^{n} \lambda_{j}=1 & \\
\lambda_{j} \geq 0 & j=1,2 \ldots n
\end{array}
$$

where $n$ is the number of DMUs whose efficiency scores are measured. $x_{1 j}, x_{2 j}, \ldots, x_{m j}$ and $y_{1 j}, y_{2 j}, \ldots, y_{s j}$ denote $m$ inputs and $s$ outputs, respectively. $o$ represents the DMU under evaluation. $\varphi$ indicates the inefficiency of the $o$-th DMU, so the efficiency is $1 / \varphi$. This model could be applied when we deal with a set of inputs and desirable outputs.

\subsection{Modeling undesirable outputs in DEA}

Most of the researches in applying DEA for efficiency evaluation focus on decreasing inputs and increasing outputs. However, sometimes there exist some specific outputs, which need to be decreased (Smith, 1990). There are many cases such as pollutant and industrial wastewater where undesirable outputs of refinery should be reduced as much as possible. There are several solutions in this condition:
A. To ignore these outputs
B. To treat these outputs as inputs and decrease them
C. To utilize the NLP to solve the DEA model
D. To make the NLP model linear with variable transformation.
E. To use the concept of directional distance function to solve the linear DEA model

Some of the most important performance evaluation models that explore the effects of undesirable outputs are as follows: 


\subsubsection{Considering undesirable outputs as inputs}

Since the target of traditional DEA models is to decrease inputs and increase desirable outputs, an appropriate approach to take the effects of undesirable outputs into account is to treat them as inputs. The most important drawback of this approach is to change nature of undesirable outputs to inputs. It is described as follow (Hua \& Bian, 2007):

$\max \varphi$

Subject to

$$
\begin{array}{lc}
\sum_{j=1}^{n} x_{i j} \lambda_{j} \leq x_{i o} & i=1,2, \ldots, m \\
\sum_{j=1}^{n} y_{b j} \lambda_{j} \leq y_{b o} & b=1,2, \ldots, t \\
\sum_{j=1}^{n} y_{r j} \lambda_{j} \geq \varphi y_{r o} & r=1,2, . ., s \\
\sum_{j=1}^{n} \lambda_{j}=1 & \\
\lambda_{j} \geq 0 & j=1,2 \ldots n
\end{array}
$$

The second row of constraints shows that this approach treats the same undesirable outputs as inputs. $y_{b j}$ represents the $b$ th undesirable output of $j$ th unit.

\subsubsection{Färe approach}

Färe et al. (1989) developed a hyperbolic output efficiency model considering undesirable output. Model (3) is a nonlinear optimization problem, which increases desirable output and decreases undesirable output, simultaneously. The model is based on strong disposability of undesirable outputs.

$\operatorname{Max} \varphi$

Subject to

$\sum_{j=1}^{n} x_{i j} \lambda_{j} \leq x_{i o} \quad i=1,2, \ldots, m$

$\sum_{j=1}^{n} y_{r j} \lambda_{j} \geq \varphi y_{r o} \quad r=1,2, . ., s$

$\sum_{j=1}^{n} y_{b j} \lambda_{j} \geq \frac{1}{\varphi} y_{b o} \quad b=1,2, \ldots, t$

$\sum_{j=1}^{n} \lambda_{j}=1$

$\lambda_{j} \geq 0 \quad j=1,2 \ldots n$

This model is the same as model (1) with an additional constraint of undesirable outputs. $t$ represents the number of undesirable outputs and other symbols are the same as model (1). The assumption of weak disposability of undesirable outputs will result in the following formulation:

$\operatorname{Max} \varphi$

Subject to

$\sum_{j=1}^{n} x_{i j} \lambda_{j} \leq x_{i o} \quad i=1,2, \ldots, m$ 


$$
\begin{array}{lr}
\sum_{j=1}^{n} y_{r j} \lambda_{j} \geq \varphi y_{r o} & r=1,2, . ., s \\
\sum_{j=1}^{n} y_{b j} \lambda_{j}=\frac{1}{\varphi} y_{b o} & b=1,2, \ldots, t \\
\sum_{j=1}^{n} \lambda_{j}=1 & \\
\lambda_{j} \geq 0 & j=1,2 \ldots n
\end{array}
$$

The difference between weak and strong disposability is derived from nature of undesirable outputs. If reducing undesirable outputs leads to produce a lower amount of desirable outputs, then weak disposability must be applied (Zofío \& Prieto, 2001). An example of this case is burning coals that produce electricity and sulfur dioxide, as desirable output and undesirable output, respectively. $20 \%$ reduction in sulfur dioxide emission causes $20 \%$ reduction in producing electricity.

\subsubsection{Seiford approach}

Seiford and Zhu (2002) proposed a model, which maintains convexity, and resolves the non-linearity problem of the Fare`s models:

\section{$\operatorname{Max} \varphi$}

Subject to

$$
\begin{array}{ll}
\sum_{j=1}^{n} x_{i j} \lambda_{j} \leq x_{i o} & i=1,2 \ldots m \\
\sum_{j=1}^{n} y_{r j} \lambda_{j} \geq \varphi y_{r o} & r=1,2 \ldots s \\
\sum_{j=1}^{n} y_{b j} \lambda_{j} \geq \varphi \bar{y}_{b o} & b=1,2 \ldots t \\
\sum_{j=1}^{n} \lambda_{j}=1 & \\
\lambda_{j} \geq 0 & j=1,2 \ldots n
\end{array}
$$

They used transformation $\bar{b}_{J}=-b_{j}+\omega \geq 0 . \omega$ is the proper transformation vector, which makes all $\bar{b}_{j}$ positive. Note that, their model is based on strong disposability of undesirable outputs.

\subsubsection{Fare approach based on directional distance function}

Färe and Grosskopf (2004) implemented the concept of directional distance function where there is weak disposability of undesirable outputs. Consider a direction vector $g=\left(g_{r}, g_{b}\right)$, and then we will have:

$$
\vec{D}\left(x^{k}, y^{k^{\prime}}, u^{k} ; g\right)=\operatorname{Max} \beta
$$

Subject to

$$
\begin{array}{ll}
\sum_{j=1}^{n} x_{i j} \lambda_{j} \leq x_{i o} & i=1,2 \ldots m \\
\sum_{j=1}^{n} y_{r j} \lambda_{j} \geq y_{r o}+\beta g_{r j} & r=1,2 \ldots s
\end{array}
$$


$\sum_{j=1}^{n} y_{b j} \lambda_{j}=\bar{y}_{b o}-\beta g_{b j} \quad b=1,2 \ldots t$

$\sum_{j=1}^{n} \lambda_{j}=1$

$\lambda_{j} \geq 0 \quad j=1,2 \ldots n$

In this model, a DMU is efficient when $\vec{D}\left(x^{k^{\prime}}, y^{k^{\prime}}, u^{k} ; g\right)=0$ and inefficiency is equal to the value of $\vec{D}\left(x^{k}, y^{k}, u^{k} ; g\right)$.

\section{Empirical results}

\subsection{Sample data}

As mentioned in section 2.2 we introduce the total number of annual accidents and the total number of annual victims as undesirable outputs. Furthermore, inputs and desirable outputs should be identified in such a way that exhibit functional characteristics of the system. In section 2.1, some variables in railway performance evaluation are mentioned. In this research, we use Labor (the number of employees), Rolling stock (the number of locomotives, the number of coaches railcars and railcars trailer), Line (the total network length of lines) as inputs, Passenger-kilometers as desirable output. The required data for inputs and desirable outputs are gathered from the International union of railways (UIC) association ("International union of railways synopsis, 2008") for a sample set of 25 European railways in 2008. In addition, the report of European railway agency is used as undesirable outputs. The UIC database contains 38 European countries railways, which due to some missing data in some fields, and since the report of European railway agency ("Railway Safety Performance in the European Union, 2010") just includes accident data of 25 countries railways; we evaluate efficiency of those railways, which mentioned in the report of European railway agency. In the UIC data, each country may contain several railway companies; we totalize these data for each country in each field. Table 1 summarizes the descriptive statistics of 25 European railways including inputs and outputs.

Table 1

Average of input and output variable values

\begin{tabular}{|c|c|c|c|c|c|c|c|}
\hline Country & \multicolumn{4}{|c|}{ Input } & \multicolumn{2}{|c|}{ Desirable } & Undesirable output \\
\hline Austria & 5755 & 43.5 & 1284 & 2603 & 10275 & 10 & 39 \\
\hline Belgium & 3513 & 37 & 624 & 3315 & 10403 & 139 & 21 \\
\hline Bulgaria & 4159 & 33 & 593 & 1380 & 2335 & 5 & 44 \\
\hline Check republic & 9487 & 57 & 1791 & 4561 & 6759 & 8 & 44 \\
\hline Denmark & 2133 & 10 & 55 & 1881 & 5843 & 0 & 12 \\
\hline Estonia & 816 & 3 & 98 & 181 & 274 & 2 & 8 \\
\hline Finland & 5519 & 10.1 & 498 & 1035 & 4052 & 1 & 21 \\
\hline France & 29901 & 162 & 4259 & 16282 & 88283 & 218 & 98 \\
\hline Germany & 33862 & 240 & 5141 & 18278 & 76997 & 31 & 164 \\
\hline Greece & 2552 & 7 & 173 & 793 & 2003 & 4 & 17 \\
\hline Hungry & 7942 & 32.71 & 61 & 2984 & 5927 & 2 & 115 \\
\hline Ireland & 1919 & 5 & 65 & 649 & 1976 & 1 & 3 \\
\hline Italy & 16862 & 93.6 & 3284 & 12358 & 46998 & 14 & 64 \\
\hline Latvia & 2263 & 14 & 200 & 491 & 951 & 7 & 40 \\
\hline Lithonia & 1765 & 11 & 252 & 363 & 398 & 1 & 29 \\
\hline Netherland & 2896 & 13 & 108 & 849 & 15313 & 3 & 20 \\
\hline Poland & 19627 & 122 & 3560 & 7224 & 17958 & 122 & 308 \\
\hline Portuguese & 2842 & 8 & 149 & 1045 & 3814 & 3 & 42 \\
\hline Romani & 10784 & 65 & 1945 & 3013 & 6880 & 67 & 208 \\
\hline Spain & 15046 & 32 & 603 & 4724 & 23344 & 19 & 46 \\
\hline Slovakia Rep & 3592 & 33.3 & 963 & 1709 & 2279 & 21 & 13 \\
\hline Slovenia & 1228 & 8 & 158 & 362 & 834 & 1 & 9 \\
\hline Sweden & 9830 & 14 & 548 & 879 & 7156 & 26 & 56 \\
\hline United kingdom & 16321 & 99 & 599 & 11552 & 51759 & 21 & 59 \\
\hline Norway & 4114 & 5 & 36 & 191 & 2705 & 12 & 1 \\
\hline
\end{tabular}




\subsection{The results}

In this section, we measure the efficiency of 25 European passenger railways using two different methods; first, the railways efficiencies scores should be estimated without considering safety measures using model (1). Then, to investigate the effects of safety measures on the efficiency scores, one of the models that were introduced in section 3.2 are employed. Note that, decreasing undesirable outputs does not necessarily decrease desirable outputs and this implies that reducing the number of railroad incidents is not achievable only by limiting the number of dispatching trains in railway network, but rather increasing the safety level would lead to diminishing the number of accidents. Hence, using strong disposability in our performance evaluation model is preferable. Models (3) and (5) are based on strong disposability assumption, whereas models (4) and (6) are based on weak disposability assumption, then models (2), (3) and (5) are applied to evaluate the performance of European passenger railways in the presence of undesirable outputs. The results of efficiency estimation of different models are presented in Table 2.

Table 2

Efficiency scores of European railways

\begin{tabular}{|c|c|c|c|c|}
\hline country & Model (1) & Model (2) & Model (3) & Model (5) \\
\hline Austria & 0.4459 & 0.4862 & 0.4459 & 0.9143 \\
\hline Belgium & 0.6124 & 1.0000 & 1.0000 & 0.9726 \\
\hline Bulgaria & 0.1310 & 0.1547 & 0.1310 & 0.9331 \\
\hline Check republic & 0.2057 & 0.2096 & 0.2057 & 0.8771 \\
\hline Denmark & 1.0000 & 1.0000 & 1.0000 & 1.0000 \\
\hline Estonia & 1.0000 & 1.0000 & 1.0000 & 1.0000 \\
\hline Finland & 0.3700 & 0.3928 & 0.3700 & 0.9789 \\
\hline France & 1.0000 & 1.0000 & 1.0000 & 1.0000 \\
\hline Germany & 0.8722 & 1.0000 & 1.0000 & 1.0000 \\
\hline Greece & 0.3185 & 0.3678 & 0.3185 & 0.9606 \\
\hline Hungry & 0.8368 & 1.0000 & 1.0000 & 0.8429 \\
\hline Ireland & 1.0000 & 1.0000 & 1.0000 & 1.0000 \\
\hline Italy & 0.8851 & 0.8959 & 0.8851 & 0.9762 \\
\hline Latvia & 0.1255 & 1.0000 & 0.1255 & 0.9336 \\
\hline Lithonia & 0.0860 & 1.0000 & 0.0860 & 0.9485 \\
\hline Netherland & 1.0000 & 1.0000 & 1.0000 & 1.0000 \\
\hline Poland & 0.3951 & 1.0000 & 0.5342 & 0.3951 \\
\hline Portuguese & 0.4894 & 1.0000 & 0.6389 & 0.9267 \\
\hline Romani & 0.2693 & 1.0000 & 0.3148 & 0.3540 \\
\hline Spain & 0.9522 & 1.0000 & 1.0000 & 0.9758 \\
\hline Slovakia Rep & 0.1325 & 0.1351 & 0.1325 & 0.9625 \\
\hline Slovenia & 0.2564 & 0.3485 & 0.2564 & 0.9896 \\
\hline Sweden & 0.4630 & 1.0000 & 0.7514 & 0.8424 \\
\hline United Kingdom & 1.0000 & 1.0000 & 1.0000 & 1.0000 \\
\hline Norway & 1.0000 & 1.0000 & 1.0000 & 1.0000 \\
\hline
\end{tabular}

Three criteria are proposed to determine which model is more appropriate among models (2), (3) and (5):

1- Discriminating power: The number of efficient DMUs determines the discriminating power of the model. It means, if the number of DMUs which are touching the efficiency boundaries are low, then the model's discriminating power is high. Table 3 summarizes efficiency scores of those models, which have been used for considering the effects of undesirable outputs. It demonstrates that model (5) with eight efficient DMUs is preferable.

2- The number of DMUs that faced with infeasibility: Infeasible DMUs are those ones denoted by Local Infeasible in the output of LINGO. Based on this criterion, 
nonlinear model (2) with five infeasible DMUs is less desirable compared with others. It should be mentioned that Local Infeasible is accepted and then, the efficiency scores of DMUs is calculated.

Table 3

Descriptive statistic for efficiency scores

\begin{tabular}{cccccc}
\hline & Min & Max & Average & Number of efficient units & Number of infeasible units \\
\hline Model (2) & 0.1351 & 1 & 0.7996 & 17 & 0 \\
Model (3) & 0.0860 & 1 & 0.6172 & 11 & 5 \\
Model (5) & 0.3540 & 1 & 0.9114 & 8 & 0 \\
\hline
\end{tabular}

3- The correlation between efficiency scores and safety measures: It is expected that increasing the number of annual railway accidents and victims, decreases the efficiency scores of DMUs. Nevertheless, some examples reject this proposition. For example, the number of undesirable outputs of German railway is more than Estonia's one, but it does not mean that the safety level of Germany`s railway is lower than Estonia. To prevent from facing with this problem, the correlation between efficiency scores and safety measures should be considered in the presence of passenger-kilometer, as a measure of railways' magnitude. Thus, partial correlation is exploited to investigate the correlation between safety measures and the results of models (2), (3) and (5). The model whose efficiency scores are more negatively correlated with undesirable outputs is more appropriate. Here, we expect that the railway whose undesirable outputs regarding its magnitude are high, gains less efficiency scores. Table 4 demonstrates that model (5) is preferred compared with others. The results presented in the third row of Table 4 show that efficiency scores of model (5) are negatively associated with both safety measures. For model (3), correlation coefficients of -0.040 and -0.194 are not statistically significant in relation to two safety measures. As for model (2), the correlation coefficients are positive in relation to safety measures. In addition, the significance level of model (5) is less than 0.05 ; it means that only the result of third row is significant in high level of confidence.

Table 4

Partial correlation results

\begin{tabular}{lccc}
\hline & & accident & Victim \\
\hline Model (2) & Correlation & 0.126 & 0.196 \\
& Significance (2-tailed) & 0.558 & 0.360 \\
\hline Model (3) & Correlation & -0.040 & -0.194 \\
& Significance (2-tailed) & 0.852 & 0.364 \\
\hline \multirow{2}{*}{ Model (5) } & Correlation & -0.450 & -0.942 \\
& Significance (2-tailed) & 0.027 & 0.000 \\
\hline
\end{tabular}

All the three criteria prove that model (5) is the most preferable model among others to assess the efficiency of European passenger railway using safety measures. The rest of this paper will compare the results of model (5) with model (1) to investigate the effects of safety measures on efficiency scores. The minimum score of output-oriented model belongs to Lithonia. Although this DMU has one of the lowest desirable output values, but the inputs values are not the worst ones. On the other hand, Romani has the lowest efficiency score in the proposed approaches. Although the maximum value of two undesirable outputs belongs to Poland, and Romani in both of them stands in the second position, but the output-oriented score of Poland is more than Romani. Then, it is eligible that the efficiency score of Romani locates in the lowest position. In model (1), 7 DMUs including: Denmark, Estonia, France, Ireland, Netherland, UK and Norway are efficient. Germany is added to these 7 DMUs, so 8 DMUs are efficient in our proposed approach. 
It is obvious that the average efficiency scores of the proposed approach that considers the effect of safety measures, is more than the basic DEA model. Moreover, it shows that if systems under evaluation are more comprehensive and more features are embedded in the model, the results are more reliable.

Fig. 1 displays a comparison of relative efficiency between the proposed approach and model (1).

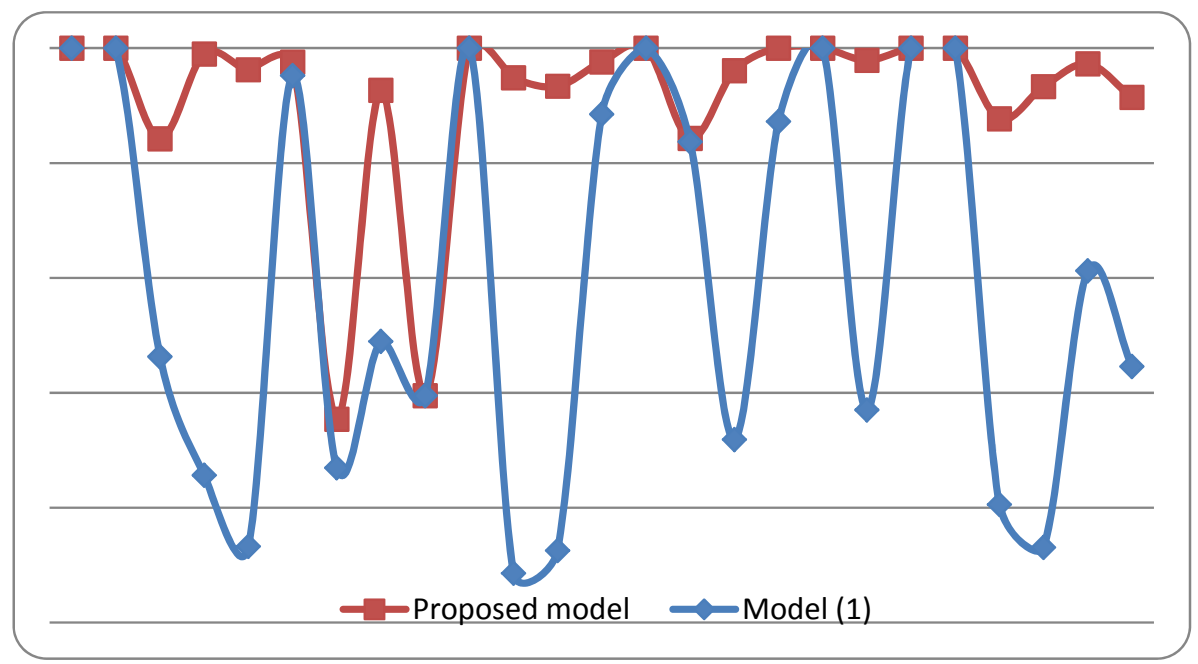

Fig. 1. Efficiency trends with and without considering safety measure

The railways under evaluation are classified in four groups based on the improvement of their efficiency scores in the proposed approach in comparison with model (1): Those railways, whose efficiency scores in model (1) are one, remain efficient in our proposed approach, like UK and Norway.

- Those railways, which are inefficient in model (1), are converted to efficient DMUs in the proposed approach. Germany is the only railway in this category.

- Those railways whose efficiency scores in model (1) are less than one and their scores increase, nevertheless they are inefficient, like: Greece, Sweden, and Belgium. In this category, the most significant improve in efficiency score is belonged to Lithonia, whose efficiency score in model (1) is the worst one. It is derived from the low value of Lithonia's undesirable output comparing to other railways.

- Last category contains railways, which have not been observed any increase in their performance or the amount is minimal. Romani, Poland and Hungry are located in this category.

\section{Conclusion}

The traditional surveys on railway performance evaluation, just utilize usual outputs like passenger-kilometer or ton-kilometers. The aim of output-oriented DEA models is to increase the outputs, but in real-world some of the systems produce undesirable output in addition to desirable ones. Safety measures are some example of undesirable outputs in performance evaluation. The proposed approach considers two undesirable outputs of railways, number of victims and number of accidents. The proposed DEA model has been applied to evaluate 25 European passenger railways based on their countries. The results have indicated that considering the undesirable outputs to evaluating European railways 
efficiency cause increasing efficiency scores of all DMUs. DMU's position which had low amount of undesirable output, were enhanced in our proposed approach.

\section{References}

Banker, R. D., Charnes, A., \& Cooper, W. W. (1984). Some models for estimating technical and scale inefficiencies in data envelopment analysis. Management science, 30(9), 1078-1092.

Chiu, Y., Huang, C., \& Ma, C. M. (2011). Assessment of China transit and economic efficiencies in a modified value-chains DEA model. European Journal of Operational Research, 209(2), 95-103.

Cowie, J. (1999). The technical efficiency of public and private ownership in the rail industry: the case of Swiss private railways .Journal of Transport Economics and Policy, 241-251.

Färe, R., \& Grosskopf, S. (2004). Modeling undesirable factors in efficiency evaluation: comment. European Journal of Operational Research, 157(1), 242-245.

Färe, R., Grosskopf, S., Lovell, C. A. K \& ,.Pasurka, C. (1989). Multilateral productivity comparisons when some outputs are undesirable: a nonparametric approach. The review of economics and statistics, 90-98.

Fielding, G. J., Babitsky, T. T., \& Brenner, M. E. (1985). Performance evaluation for bus transit. Transportation Research Part A: General, 19(1), 73-82.

Hua, Z., \& Bian, Y. (2007). DEA with undesirable factors. Modeling Data Irregularities and Structural Complexities in Data Envelopment Analysis, 103-121.

International union of railways synopsis, 2008. from http://www.uic.org/spip.php?article1347

Jain, P., Cullinane, S., \& Cullinane, K. (2008). The impact of governance development models on urban rail efficiency. Transportation Research Part A: Policy and Practice, 42(9), 1238-125.0

Karlaftis, M. G. (2004). A DEA approach for evaluating the efficiency and effectiveness of urban transit systems. European Journal of Operational Research, 152(2), 354-364.

Lawrence, W., \& Erwin, T. (2003). Technical efficiency and service effectiveness for railways industry: DEA approaches. Journal of the Eastern Asia Society for Transportation Studies, 5.

Oum, T. H., \& Yu, C. (1994). Economic efficiency of railways and implications for public policy: a comparative study of the OECD countries' railways. Journal of Transport Economics and Policy, 121-138.

Railway Safety Performance in the European Union 2010. from http://www.era.europa.eu/DocumentRegister/Pages/railway-safety-performance-in-european-union-2010.aspx

Seiford, L. M., \& Zhu, J .(2002) .Modeling undesirable factors in efficiency evaluation. European Journal of Operational Research, 142(1), 16-20.

Smith, P. (1990). Data envelopment analysis applied to financial statements. Omega, 18(2), 131-138.

Yu, M. M., \& Lin, E. T. J. (200 .(8Efficiency and effectiveness in railway performance using a multi-activity network DEA model. Omega, 36(6), 1005-1017.

Zofío, J. L., \& Prieto, A. M. (2001). Environmental efficiency and regulatory standards: the case of $\mathrm{CO} 2$ emissions from OECD industries. Resource and Energy Economics, 23(1), 63-83. 